\title{
Cassava Pulp Hydrolysis under Microwave Irradiation with Oxalic Acid Catalyst for Ethanol Production
}

\author{
Euis Hermiati ${ }^{1, *}$, Shuntaro Tsubaki ${ }^{2,3}$ \& Jun-ichi Azuma ${ }^{2,4}$ \\ ${ }^{1} \mathrm{R} \& D$ Unit for Biomaterials, Indonesian Institute of Sciences (LIPI), \\ Jalan Raya Bogor Km 46, Cibinong, Bogor 16911, Indonesia \\ ${ }^{2}$ Graduate School of Agriculture, Kyoto University, Sakyo-ku, Kyoto 606-8502, Japan \\ ${ }^{3}$ Oceanography Section, Science Research Center, Kochi University, \\ Akebono-cho, 2-5-1, 780-8520, Kochi, Japan \\ ${ }^{4}$ Graduate School of Engineering, Osaka University, \\ Yamadaoka, Suita, 565-0871, Osaka, Japan \\ *Email: euis.hermiati@lipi.go.id
}

\begin{abstract}
Microwave irradiation is an alternative method of starch hydrolysis that offers a rapid process. The aim of this research was to improve microwaveassisted hydrolysis of cassava pulp by using oxalic acid as a catalyst. Suspension of cassava pulp in $0.5 \%$ oxalic acid $(1 \mathrm{~g} / 20 \mathrm{~mL})$ was subjected to microwave irradiation at $140-230^{\circ} \mathrm{C}$ for 5 minutes, with 4 minutes of pre-heating. One gram of fractured activated carbon made of coconut shell was added into a number of suspensions that were subjected to the same conditions of microwave irradiation. The soluble fraction of the hydrolysates was analyzed for its total soluble solids, malto-oligomer distribution, glucose content, $\mathrm{pH}$ value, and formation of brown compounds. The effects of the combined severity parameter at a substrate concentration of $5-12.5 \%$ on the glucose yield were also evaluated. The highest glucose yield $\left(78 \%\right.$ of dry matter) was obtained after hydrolysis at $180^{\circ} \mathrm{C}$ without activated carbon addition. Heating above $180^{\circ} \mathrm{C}$ reduced the glucose yield and increased the $\mathrm{pH}$ and the formation of brown compounds. The use of activated carbon in microwave-assisted acid hydrolysis of cassava pulp reduced the glucose yield, but suppressed the formation of brown compounds. The highest glucose yield ( $70-80 \%$ of dry matter) was attained at a severity parameter of 1.3-1.5.
\end{abstract}

Keywords: activated carbon; cassava pulp; glucose; hydrolysis; microwave; oxalic acid; severity parameter.

\section{$1 \quad$ Introduction}

Cassava pulp, which is generated by the tapioca industry, contains a significant amount of carbohydrates, especially starch. The starch contained in cassava pulp varies, notably in relation to the efficiency of the starch extraction from the cassava. The starch content in cassava pulp can be as low as $40 \%$ [1] and can be as high as $68 \%[2,3]$, or even $79 \%$ when the cassava pulp is obtained from the

Received October $29^{\text {th }}, 2013,1^{\text {st }}$ Revision November $20^{\text {th }}, 2013,2^{\text {nd }}$ Revision May $8^{\text {th }}, 2014$ Accepted for publication May $13^{\text {th }}, 2014$.

Copyright $@ 2014$ Published by ITB Journal Publisher, ISSN: 2337-5760, DOI: 10.5614/j.math.fund.sci.2014.46.2.2 
tapioca home industry in the area of Bogor, West Java [4,5]. Since starch is the major component of cassava pulp, hydrolysis of starch to glucose can be an important process to better utilize this tapioca industry by-product. Studies on the hydrolysis of starch in cassava pulp have been performed by a number of researchers using several methods, such as acid hydrolysis [6-8], enzymatic hydrolysis [9-15], a hydrothermal process [16,17], a combination of hydrothermal and enzymatic hydrolysis $[18,19]$, and a combination of ionic liquids and enzymatic hydrolysis [20]. Acid hydrolysis of cassava pulp requires less time and is more efficient than enzymatic hydrolysis. Enzymatic hydrolysis usually takes several days to complete and the production costs may be high due to the high cost of the enzymes. However, the formation of some inhibitors, such as furfural and 5-hydroxymethylfurfural (5-HMF), during acid hydrolysis can become a problem if the sugar produced is further fermented. On the other hand, there is no risk of the formation of those inhibitors during enzymatic hydrolysis.

Microwave-assisted hydrolysis of starch is a promising method of starch hydrolysis, especially due to its simplicity and rapid process. Our previous experiments have shown that cassava pulp hydrolysis under microwave irradiation can be conducted either in water or in acid medium. When water medium was used for the hydrolysis, it was found that the maximum glucose yield was obtained after hydrolysis at $230^{\circ} \mathrm{C}$ for 5 minutes $(28.59 \%$ of dry matter or $32.41 \%$ of theoretical yield) [4]. When some activated carbon was added, glucose yield markedly increased up to $44.49 \%$ (of theoretical yield) at a temperature of $220^{\circ} \mathrm{C}$ for 5 minutes and up to $52.3 \%$ (of theoretical yield) at a temperature of $210^{\circ} \mathrm{C}$ for 15 minutes [5]. However, these results were still lower than those of enzymatic hydrolysis $(70-74 \%)[13,14]$, or the combination of hydrothermal and enzymatic hydrolysis $( \pm 75 \%)[18,19]$. In this experiment, we tried to use acid catalyst to increase the glucose yield. Sulfuric and hydrochloric acids are the most widely used acids for hydrolysis. However, the application of sulfuric acid produces gypsum $\left(\mathrm{CaSO}_{4}\right)$ resulting from the neutralization of sulfuric acid with lime [21], while the application of hydrochloric acid in starch hydrolysis presents a number of other problems, such as the need of a desalination process of the glucose syrup using high-cost ion exchange resins after the neutralization of the hydrolysate [22]. In this study oxalic acid $\left(\mathrm{H}_{2} \mathrm{C}_{2} \mathrm{O}_{4}\right)$ was used to improve the hydrolysis of the carbohydrates, especially starch, in the cassava pulp. Oxalic acid is a dibasic organic acid that is widely used for metal and textile treatment, bleaching agent, leather tanning, and marble polishing. In Japan oxalic acid is used as a hydrolysis catalyst for the production of millet jelly. The acid is neutralized by the addition of calcium hydroxyde and is removed from the product as calcium oxalate. This acid was chosen because it is classified as an organic but strong acid with two carboxylic 
functional groups. Besides, there are only a few studies regarding the application of this acid as a catalyst in the hydrolysis of carbohydrates.

Activated carbon has been proved to improve saccharification of starch in water medium [5,23]. It can also adsorb the brown compounds produced by the thermohydrolysis [5]. This process is beneficial if the glucose obtained is further fermented, for example for ethanol production. The lighter color of the glucose syrup can also make the product look more attractive. Thus, it is worth knowing whether the activated carbon also acts the same way in oxalic acid.

Experiments on the hydrolysis of cassava pulp, either enzymatically or using acids, are mostly conducted at low substrate concentrations, for example 4-5\% $(w / v)$. There are only a few reports regarding the use of a high substrate concentration or a high solid liquid ratio of cassava pulp in the hydrolysis of cassava pulp $[7,9,14,18]$. In fact, an efficient process of ethanol production from sugars needs a high concentration of sugars in the hydrolysate, which can be obtained if a high substrate concentration is used in the hydrolysis. Therefore, in this study hydrolysis of cassava pulp using oxalic acid catalyst was performed at low and high substrate concentrations.

A severity concept that combines time and temperature has been developed to control the extent of pulping and the prehydrolysis processes in the pulp and paper industry [24]. This concept was extended by taking into account the acid catalyst used in the process, so that it becomes a combined severity parameter; therefore, different combinations of reaction time, temperature and acid catalyst concentration can be unified to produce the severity parameter [24-26]. The effects of the severity parameter on the results of the hydrolysis, for example the glucose yield, can be plotted as scattered points in a chart. This chart is useful to determine the combination of reaction time, temperature and acid concentration that produce a high glucose yield. Therefore, effects of the severity parameters were also studied, so that this study provides some new information regarding the relation between the severity parameter and the glucose yield obtained from the microwave-assisted hydrolysis of cassava pulp in acid medium.

\section{$2 \quad$ Methods}

\subsection{Materials}

The cassava pulp used in this study was pulp as used in our previous studies, with starch as the main component (79.45\%) [4,5]. The fractured type activated carbon made of coconut shell used in this study (Y-10S AW, Ajinomoto FineTecno Co., Inc. (AFT), Japan) was the same as that used in our previous study 
[5,27]. Analytical grades of solvents and other reagents were purchased from local chemical suppliers.

\subsection{Cassava Pulp Hydrolysis Using Microwave Irradiation}

The cassava pulp was suspended in $0.5 \%$ oxalic acid $(1 \mathrm{~g} / 20 \mathrm{~mL})$ and put in a $100 \mathrm{~mL}$ Teflon ${ }^{\circledR}$ tube. The suspension was homogenized by stirring. Some suspensions were added with activated carbon $(1 \mathrm{~g})$, and some others were not. All the samples were heated in a MycroSYNTH Lab Station $(2,450 \mathrm{MHz})$ microwave oven (Milestone Inc., Shelton, CT, USA) one at a time, at a temperature of $140-230^{\circ} \mathrm{C}$ with a pre-heating time of 4 minutes and a heating time of 5 minutes. The microwave oven used was a multimode microwave oven, equipped with a thermocouple thermometer and a PID (Proportional Integral Derivative) controller to monitor and control the temperature inside the reactor real time. After heating in the microwave, the samples were put in an ice bath for immediate cooling.

\subsection{Determination and Analysis of Soluble Fraction}

Hydrolysates of microwave treated cassava pulp were centrifuged at $10^{\circ} \mathrm{C}$, $5,000 \mathrm{~g}$ for 15 minutes. After separation from their supernatant, residues of the hydrolysates were washed using $30 \mathrm{~mL}$ of water, followed by centrifugation at $10^{\circ} \mathrm{C}, 5,000 \mathrm{~g}$ for 15 minutes. The washing and centrifugation were conducted for three times and followed by freeze-drying the residues. The total soluble solids ( ${ }^{\circ}$ Brix) in the hydrolysates were determined using an ATAGO Hand Refractometer N-20. Besides that, the soluble fraction was also calculated by using formula in Eq. (1).

$$
\begin{aligned}
& \text { Soluble fraction }(\%)= \\
& \frac{\text { Weight of raw material - weight of residue }}{\text { Weight of raw material }} \times 100
\end{aligned}
$$

Distribution of maltooligomers was analyzed using high performance liquid chromatography (HPLC) with $7.5 \times 200 \mathrm{~mm}$ MCI GEL CK04SS column, Shodex SE-51 refractive index detector, Jasco PU-980 pump, Jasco CO-965 column oven, Jasco DG-980-50 degasser, and water as a solvent. The elution rate of the water was $0.3 \mathrm{~mL} /$ minutes. The calculation was accomplished by a Jasco Chrom NAV data station. A Glucose CII test kit (Wako Junyaku, Co., Osaka) was used for the determination of the glucose content. The $\mathrm{pH}$ value of the hydrolysate was determined using a $\mathrm{pH}$ meter and the brown compound intensity was determined by measuring absorbance at $490 \mathrm{~nm}$ using a UV-Vis Spectrophotometer $[28,29]$. 


\subsection{The Effects of Combined Severity Parameter}

The combined severity parameter of the hydrothermal treatment with addition of acid catalyst was performed at a number of combinations of temperatures $\left(140-230^{\circ} \mathrm{C}\right)$ and acid concentrations $(0.1-2.68 \%$ or $\mathrm{pH} 1.21-2.27)$ at a substrate concentration of $5-12.5 \%$. The heating processes were conducted in 5 minutes. The combined severity parameter was calculated using the formula in Eq. (2) $[24,25]$.

$$
\log R_{0}=\log \left[\mathrm{H}^{+}\right] t \exp \left(\frac{T-100}{14.75}\right)
$$

where $\left[\mathrm{H}^{+}\right]$is determined from the $\mathrm{pH}$ of the acid, $t$ is reaction time (minutes), and $T$ is heating temperature $\left({ }^{\circ} \mathrm{C}\right)$, respectively.

\subsection{Analysis of Residues}

The residues of cassava pulp were analyzed for their morphological properties by SEM Zeiss Evo50-05-87.

\section{$3 \quad$ Results and Discussion}

\subsection{The Effects of Heating Temperature}

Microwave-assisted hydrolysis of cassava pulp with oxalic acid catalyst could solubilize almost all chemical components of the material. Even at the lowest heating temperature in the experiment $\left(140^{\circ} \mathrm{C}\right)$ there was around $90 \%$ soluble fraction in the hydrolysate (Table 1). The soluble fraction in the cassava pulp hydrolysates increased as the heating temperature was increased up to $180^{\circ} \mathrm{C}$, but it was relatively constant when the temperature was further increased up to $220^{\circ} \mathrm{C}$. The soluble fraction in the hydrolysate decreased after heat treatment at $230^{\circ} \mathrm{C}$. The total soluble solids in the hydrolysates of cassava pulp also increased as the heating temperature was increased up to $180^{\circ} \mathrm{C}$, but it decreased when the heating temperature was further increased up to $230^{\circ} \mathrm{C}$. These data have good correlation with the results of the determination of soluble fractions.

Since starch is the major component of cassava pulp, the soluble fraction in the hydrolysates mostly contained maltodextrins and maltooligomers. There was still a high molecular weight component observed in the hydrolysates after heat treatment at $140^{\circ} \mathrm{C}$. However, that component almost disappeared after heat treatment at $150^{\circ} \mathrm{C}$ (Figure 1A). When the heating temperature was further increased, the maltooligomers dissapeared gradually, and when the heating temperature was above $160^{\circ} \mathrm{C}$ only the glucose component was observed. 
Beside starch, some hemicelluloses may also be solubilized during the heat treatment in oxalic acid medium, because cassava pulp also contains hemicelluloses. Microwave-assisted hydrolysis of cassava pulp in water medium shows that hemicelluloses are gradually solubilized as the heating temperature increases [4].

Table 1 Soluble fraction and total soluble solids of cassava pulp hydrolysates after microwave heating at $140-230^{\circ} \mathrm{C}$ in oxalic acid medium with and without activated carbon (AC).

\begin{tabular}{ccccc}
\hline \multirow{2}{*}{$\begin{array}{c}\text { Temperature } \\
\left({ }^{\circ} \mathbf{C}\right)\end{array}$} & \multicolumn{2}{c}{ Soluble fraction (\%) } & \multicolumn{2}{c}{ Total soluble solids ( ${ }^{\circ}$ Brix) } \\
\cline { 2 - 5 } & without AC & with AC & without AC & with AC \\
\hline 140 & $89.54 \pm 1.04$ & $84.07 \pm 0.16$ & $4.10 \pm 0.14$ & $3.85 \pm 0.07$ \\
150 & $90.53 \pm 0.38$ & $80.06 \pm 1.51$ & $4.20 \pm 0.00$ & $3.65 \pm 0.07$ \\
160 & $91.08 \pm 0.72$ & $74.75 \pm 0.08$ & $4.30 \pm 0.00$ & $3.60 \pm 0.00$ \\
170 & $91.59 \pm 0.54$ & $73.74 \pm 0.40$ & $4.30 \pm 0.00$ & $3.40 \pm 0.00$ \\
180 & $92.59 \pm 0.13$ & $76.11 \pm 0.56$ & $4.45 \pm 0.07$ & $3.30 \pm 0.00$ \\
190 & $92.49 \pm 0.42$ & $76.39 \pm 1.44$ & $4.35 \pm 0.07$ & $3.30 \pm 0.00$ \\
200 & $92.56 \pm 0.25$ & $77.02 \pm 0.56$ & $4.20 \pm 0.00$ & $3.20 \pm 0.00$ \\
210 & $92.30 \pm 0.31$ & $76.51 \pm 1.28$ & $4.00 \pm 0.00$ & $3.05 \pm 0.07$ \\
220 & $91.86 \pm 0.31$ & $74.64 \pm 0.24$ & $3.95 \pm 0.07$ & $2.90 \pm 0.00$ \\
230 & $89.72 \pm 0.93$ & $71.25 \pm 1.03$ & $3.50 \pm 0.14$ & $2.35 \pm 0.07$ \\
\hline
\end{tabular}

The glucose yield obtained from microwave-assisted hydrolysis of cassava pulp in oxalic acid medium increased as the heating temperature was increased (Figure 2). The highest glucose yield (78\%) was attained at a heating temperature of $180^{\circ} \mathrm{C}$. This means that almost all starch in the cassava pulp was hydrolyzed to glucose. The maximum glucose yield obtained was higher than the result of cassava pulp hydrolysis using enzymes (70\%) [13] or the combination of hydrothermal and enzymatic hydrolysis $(75 \%)[18,19]$, but lower than the process reported by Thongchul, et al. [30], who applied acid hydrolysis using hydrocholric acid, sulfuric acid and phosphoric acid with a high acid concentration $(0.25-2 \mathrm{~N})$ and conventional heating at $121^{\circ} \mathrm{C}, 15 \mathrm{psig}$ for 15-60 minutes. The glucose yield gradually decreased when the heating temperature was further increased up to $230^{\circ} \mathrm{C}$. This was due to the degradation of the glucose to lower molecular weight compounds, such as 5-HMF or the reaction of glucose with the amino group from the protein in the cassava pulp (Maillard reaction) that also resulted in the formation of the 5-HMF compound. The increase of absorbance at $490 \mathrm{~nm}$, (Figure 3) is one of the indicators that the degradation of sugars, including glucose, in the cassava pulp hydrolysate increased with the increase of the heating temperature. The absorbance greatly 
increased when cassava pulp hydrolysis was conducted at temperatures above $180^{\circ} \mathrm{C}$, which was concurrent with a decreasing glucose yield.

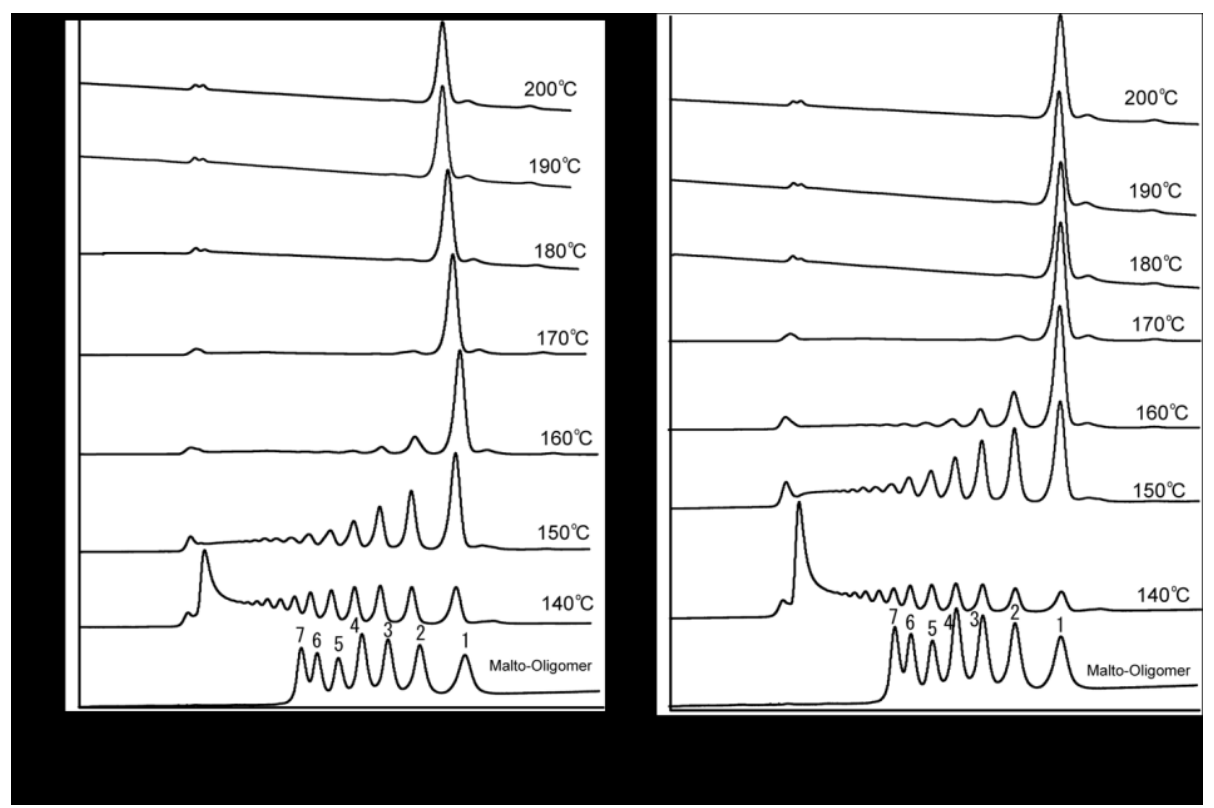

Figure 1 Distribution of maltooligomers in cassava pulp hydrolysates after microwave heating at $140-200^{\circ} \mathrm{C}$ in oxalic acid medium without activated carbon (A) and with activated carbon (B).

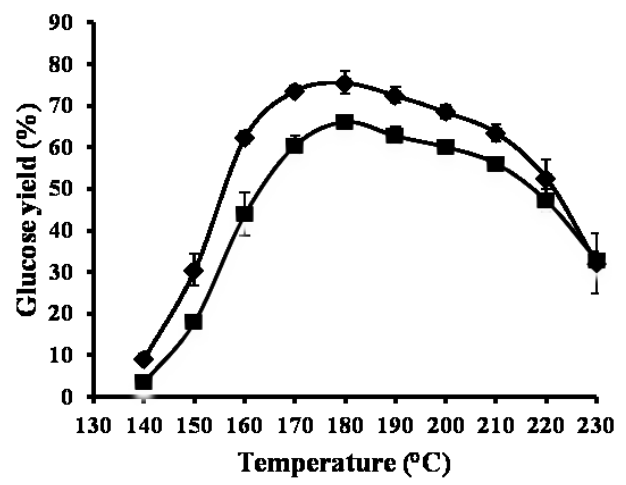

Figure 2 Glucose yield obtained from hydrolysis of cassava pulp under microwave irradiation in oxalic acid medium at $140-230^{\circ} \mathrm{C}$ (spade $=$ without activated carbon; rectangle $=$ with activated carbon).

The $\mathrm{pH}$ of cassava pulp hydrolysates increased with the increase of the heating temperature (Table 2). This was opposite to the $\mathrm{pH}$ value of the hydrolysates 
from the hydrolysis of cassava pulp in water medium $[4,31]$. The increase of the $\mathrm{pH}$ value during the microwave-assisted acid hydrolysis of cassava pulp may be due to the decrease of the hydrogen ion concentration in the hydrolysates, since these hydrogen ions were used for the hydrolysis of carbohydrates in the cassava pulp, especially starch. During the hydrolysis a number of other organic and weak acids, such as acetic acid, formic acid or levulinic acid, may be formed. However, since they were weak acids, they do not contribute too much to the availability of hydrogen ions in the hydrolysates. Hence, the $\mathrm{pH}$ of the hydrolysates increases.

Table 2 The $\mathrm{pH}$ of cassava pulp hydrolysates after microwave heating at 140$230^{\circ} \mathrm{C}$ in oxalic acid medium with and without activated carbon (AC).

\begin{tabular}{ccc}
\hline \multirow{2}{*}{$\begin{array}{c}\text { Temperature } \\
\left({ }^{\circ} \mathbf{C}\right)\end{array}$} & \multicolumn{2}{c}{$\mathbf{p H}$} \\
\cline { 2 - 3 } 140 & $1.79 \pm 0.12$ & $2.10 \pm 0.01$ \\
150 & $1.81 \pm 0.12$ & $2.09 \pm 0.02$ \\
160 & $1.82 \pm 0.12$ & $2.07 \pm 0.02$ \\
170 & $1.80 \pm 0.12$ & $2.06 \pm 0.03$ \\
180 & $1.97 \pm 0.18$ & $2.19 \pm 0.04$ \\
190 & $2.07 \pm 0.13$ & $2.24 \pm 0.05$ \\
200 & $2.46 \pm 0.08$ & $2.53 \pm 0.00$ \\
210 & $2.77 \pm 0.05$ & $2.77 \pm 0.16$ \\
220 & $2.83 \pm 0.04$ & $2.86 \pm 0.08$ \\
230 & $2.88 \pm 0.09$ & $2.93 \pm 0.11$ \\
\hline
\end{tabular}

The formation of brown compounds in the cassava pulp hydrolysates can be used as an indicator of the degradation of sugars produced from the hydrolysis of the material, which can be observed by measuring the absorbance value at $490 \mathrm{~nm}[28,29]$. The absorbance was relatively low and constant up to a heating temperature of $170^{\circ} \mathrm{C}$. It started to increase when the heating temperature reached $180^{\circ} \mathrm{C}$ (Figure 3), which coincided with the maximum glucose yield obtained. Starting from this temperature, increasing the heating temperature decreased the glucose yield and at the same time increased the absorbance value at $490 \mathrm{~nm}$. This means that at $180^{\circ} \mathrm{C}$ some of the glucose and other sugars produced during the hydrolysis started to decompose to lower molecular weight compounds, such as 5-HMF and furfural, which easily forms polymerised dark colored materials. The absorbance values of brown compounds in the acid hydrolysates obtained in this experiment were lower than those obtained from the experiment in water medium at a hydrolysis temperature of 180 and $190^{\circ} \mathrm{C}$ [4]. In acid medium, the amino group of the protein contained in the cassava 
pulp was protonated, thus, the formation of glycosylamine, the initial step of the Maillard reaction, was suppressed. Therefore, with some amount of heating, in this case up to $190^{\circ} \mathrm{C}$, the formation of the brown compounds in acid medium could also be suppressed. However at temperatures higher than $190^{\circ} \mathrm{C}$, the 490 $\mathrm{nm}$ absorbance values of the acid hydrolysates did not differ very much from those of water hydrolysates.

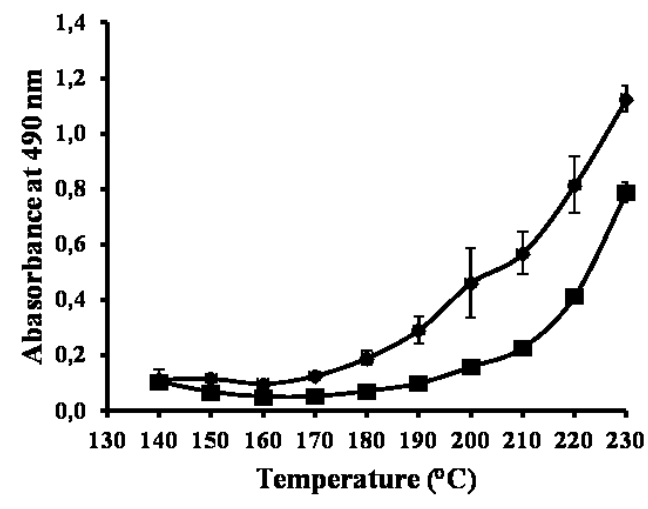

Figure 3 Brown compound of cassava pulp hydrolysates after microwave irradiation at $140-230^{\circ} \mathrm{C}$ in oxalic acid medium (spade = without activated carbon; rectangle $=$ with activated carbon).

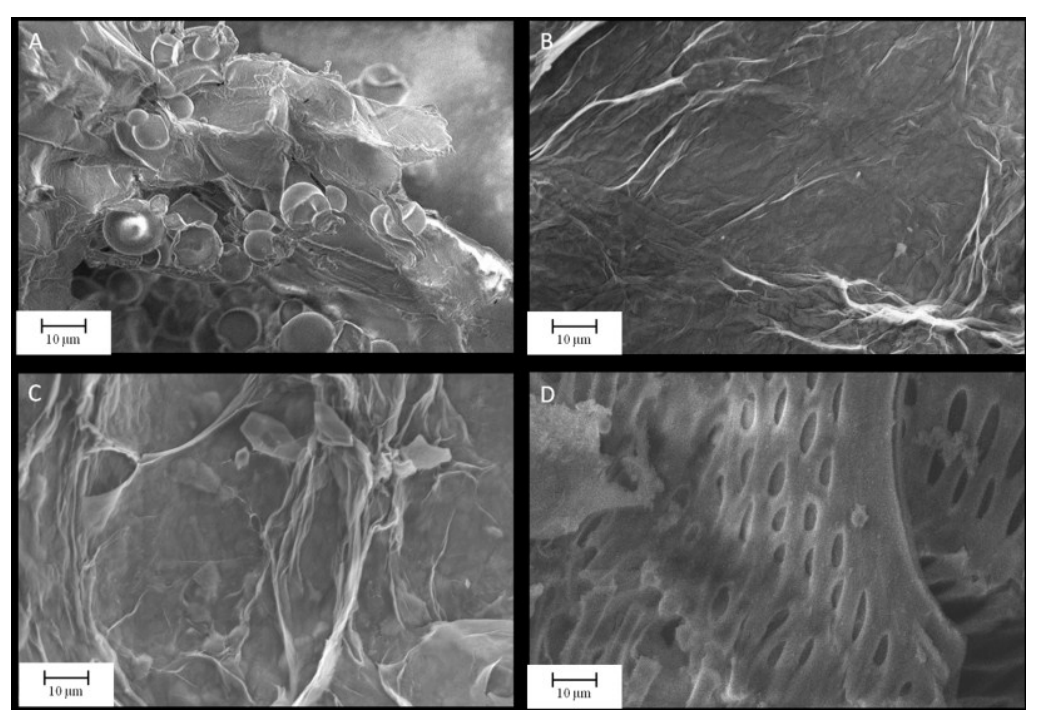

Figure 4 SEM images of native cassava pulp (A) and residues of cassava pulp after microwave irradiation at $140^{\circ} \mathrm{C}(\mathrm{B}), 180^{\circ} \mathrm{C}(\mathrm{C})$ and $220^{\circ} \mathrm{C}(\mathrm{D})$. 
SEM images of the native cassava pulp and the residues of cassava pulp are shown in Figure 4. It can be seen that attached starch granules in the native cassava pulp (Figure 4A) had disappeared after the material was hydrolyzed under microwave irradiation at $140^{\circ} \mathrm{C}$ with oxalic acid catalyst (Figure 4B). The matrix of cassava pulp did not show any difference at heating temperatures of $140^{\circ} \mathrm{C}$ and $180^{\circ} \mathrm{C}$ (Figures $4 \mathrm{~B}$ and $4 \mathrm{C}$ ). However, the fiber matrix shows a different structure when hydrolysis was conducted at $220^{\circ} \mathrm{C}$, which indicates a loss of hemicelluloses from the fiber matrix (Figure 4D).

\subsection{The Effects of Activated Carbon Addition}

There were changes of the cassava pulp hydrolysates characteristics when activated carbon was added to the suspension of cassava pulp before microwave heating. The soluble fraction and the total soluble solids in the hydrolysates continuously decreased as the heating temperature increased from 140 to $230^{\circ} \mathrm{C}$. This trend was different from that without activated carbon addition. The percentage of the soluble fraction as well as the degrees of Brix were also lower than those in the hydrolysates without activated carbon. However, there were similar patterns in the formation of glucose and brown compounds and the changes of $\mathrm{pH}$ between those hydrolysates without and with the addition of activated carbon, even though there were differences in the amount of glucose yields, $\mathrm{pH}$ values, and intensities of brown compounds between the two. These phenomena may originate from a small amount of adsorptive capacity of maltooligosaccahrides on the activated carbon used in the present study, because differences in adsorbability of monomeric glucose and malto-oligosaccharides on activated carbons remarkably affects the yield of glucose [23,32]. Activated carbon can adsorb chemical components in the hydrolysate on its surface. The amount and types of chemicals adsorbed depend on the size of the pores on the surface of the activated carbon as well as the molecular size of the chemicals. The higher the temperature of heating, the higher the low molecular weight compounds formed as a result of the degradation of chemical components in the cassava pulp; thus, the more of these solubles are adsorbed on the surface of the activated carbon. This may further cause a decrease of the solubles in the hydrolysates with activated carbon addition. The activated carbon used in the hydrolysis also adsorbed some acids, including the oxalic acid medium as well as the acid formed during the hydrolysis. Hence, the $\mathrm{pH}$ values of the hydrolysates obtained from the process with activated carbon were higher than those from the process without activated carbon. However, this phenomenon did not agree with the results of previous studies on the microwave-assisted hydrolysis of cassava pulp in water medium [5] and sulfuric acid medium [27], which showed that the $\mathrm{pH}$ values of the hydrolysates obtained from the process with activated carbon were lower than those from the process without activated carbon. Elaborate study is needed to better understand this phenomenon. 
Despite its negative effect on the reduction of glucose yield in the acid hydrolysates, the addition of activated carbon during the hydrolysis adsorbed the brown compounds in the hydrolysates, so a lighter color of the hydrolysates was obtained. This is also beneficial when the hydrolysates are further fermented using microbes, such as $S$. serevisiae.

\subsection{The Effects of Combined Severity Parameter on Glucose Yield}

An efficient fermentation of glucose to ethanol needs quite a high glucose concentration in the hydrolysates. This can be achieved by increasing the substrate concentration in the hydrolysates. We tried to use a combined severity parameter to obtain an optimum condition of the microwave-assisted acid hydrolysis of cassava pulp at different substrate concentrations (5-12.5\%). The analysis of the combined severity parameter shows that the highest glucose

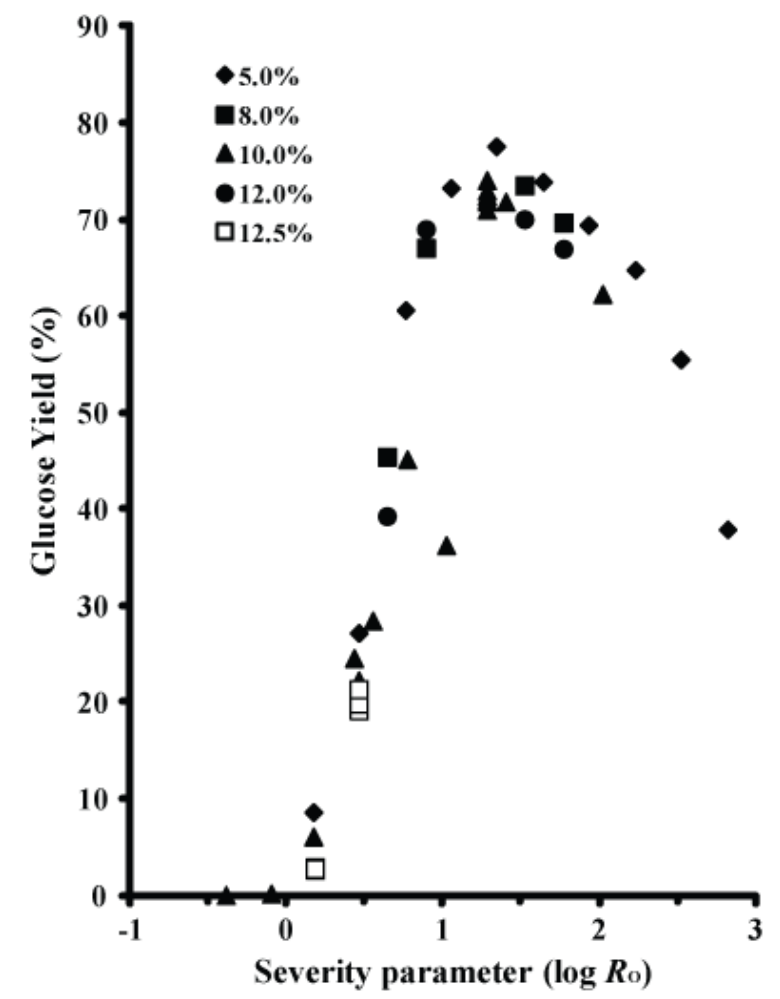

Figure 5 The effects of severity parameters in the microwave-assisted acid hydrolysis of cassava pulp at different substrate concentration on the glucose yield. 
yield $(>70 \%)$ from the different substrate concentrations was attained at a severity parameter of 1.3-1.5 (Figure 5). The glucose yield was lower at a severity parameter less than 1.3 , probably due to less energy available to break down the glycosidic bond of the starch. The glucose yield was also lower at a severity parameter higher than 1.5 , which may be caused by the degradation of the glucose to lower molecular weight compounds such as 5-HMF. Based on this analysis, we can choose microwave-assisted acid hydrolysis conditions (time, temperature, acid concentration), which combination of these three factors resulted in a combined severity parameter of 1.3-1.5. At this level of the severity parameter the highest glucose yield could be obtained with a minimum degradation of the sugar to 5-HMF, so that it supported fermentation of the sugar to ethanol.

\section{Conclusions}

Microwave-assisted hydrolysis with oxalic acid catalyst is a potential process to produce glucose from cassava pulp, since it can produce hydrolysate with a high glucose yield and a light color, and the process can be completed in a short time. The glucose obtained can be further fermented to produce bioethanol for fuel. The use of activated carbon in the microwave-assisted hydrolysis of cassava pulp in oxalic acid medium contributed to produce a lighter colored saccharified solution without too much effect on the glucose yield. The combined severity parameter can be useful in predicting or designing hydrolysis conditions of cassava pulp to produce hydrolysates with a high glucose yield, so that the hydrolysate can be better fermented to produce ethanol.

\section{Acknowledgements}

The authors gratefully acknowledge the Ministry of Research and Technology of The Republic of Indonesia for providing the internship program to the first author for conducting this research at Kyoto University from October until November 2010.

\section{References}

[1] Li, P. \& Zhu, M., A Consolidated Bio-processing of Ethanol from Cassava Pulp Accompanied by Hydrogen Production, Bioresource Technol., 102, pp. 10471-10479, 2011.

[2] Sriroth, K., Chollakup, R., Chotineeranat, S., Piyachomkwan, K. \& Otes, C.G., Processing of Cassava Waste for Improved Biomass Utilization, Bioresource Technol., 71, pp. 63-69, 2000.

[3] Kunhi, A.A.M., Ghildyal, N.P., Lonsane, B.K., Ahmed, S.Y. \& Natarajan, C.P., Studies on Production of Alcohol from Saccharified 
Waste Residue from Cassava Starch Processing Industries, Starch/Stärke, 33, pp. 275-279, 1981.

[4] Hermiati, E., Azuma, J., Mangunwidjaja, D., Sunarti, T.C., Suparno, O. \& Prasetya, B., Hydrolysis of Carbohydrates in Cassava Pulp and Tapioca Flour under Microwave Irradiation, Indo. J. Chem., 11, pp. 238245, 2011.

[5] Hermiati, E., Azuma, J., Tsubaki, S., Mangunwidjaja, D., Sunarti, T.C., Suparno, O. \& Prasetya, B., Improvement of Microwave-Assisted Acid Hydrolysis of Cassava Pulp and Tapioca Flour under Microwave Irradiation, Carbohyd. Polym., 87, pp. 939-942, 2012.

[6] Ahmed, S.Y., Ghildyal, N.P., Kunhi, A.A.M. \& Lonsane, B.K., Confectioner's Syrup from Tapioca Processing Waste, Starch/Stärke, 35, pp. 430-432, 1983.

[7] Srikanta, S., Jaleel, S.A., Ghildyal, N.P., Lonsane, B.K. \& Karanth, N.G., Novel Technique for Saccharification of Cassava Fibrous Waste for Alcohol Production, Starch/Stärke, 39, pp. 234-237, 1987.

[8] Woiciechowski, A.L., Nitsche, S., Pandey, A. \& Soccol, C.R., Acid and Enzymatic Hydrolysis to Recover Reducing Sugars from Cassava Bagasse: An Economic Study, Braz. Arch. Biol. Techn., 45(3), pp. 393400, 2002.

[9] Jaleel, S.A., Srikanta, S., Ghildyal, N.P. \& Lonsane, B.K., Simultaneous Solid Phase Fermentation and Saccharification of Cassava Fibrous Residue for Production of Ethanol, Starch/Stärke, 40, pp. 55-58, 1988.

[10] Chotineeranat, S., Pradistsuwana, C., Siritheerasas, P. \& Tantratian, S., Reducing Sugar Production from Cassava Pulp Using Enzymes and Ultra-filtration I: Enzymatic Hydrolation, J. Sci. Res. Chula. Univ., 29(2), pp. 119-128, 2004.

[11] Kongkiattikajorn, J. \& Yoonan, K., A Study of Optimal Conditions for Reducing Sugars Production from Cassava Peels by Diluted Acid and Enzymes, Kasetsart J. (Nat. Sci.), 38, pp. 29-35, 2004.

[12] Srinorakutara, T., Kaewvimol, L. \& Saengow, L., Approach of Cassava Waste Pretreatments for Fuel Ethanol Production in Thailand, J. Sci. Res. Chula. Univ., 31, pp. 77-84, 2006.

[13] Rattanachomsri, U., Tanapongpipat, S., Eurwilaichitr, L. \& Champreda, V., Simultaneous Non-Thermal Saccharification of Cassava Pulp by Multi-Enzyme Activity and Ethanol Fermentation by Candida Tropicalis, J. Biosci. Bioeng., 107, pp. 488-493, 2009.

[14] Zhu, M., Li, P., Gong, X. \& Wang, J., A Comparison of The Production of Ethanol Between Simultaneous Saccharification and Fermentation and Separate Hydrolysis and Fermentation Using Unpretreated Cassava Pulp and Enzyme Cocktail, Biosci. Biotech. Bioch., 76, pp. 671-678, 2012.

[15] Virunanon, C., Ouephanit, C., Burapatana, V. \& Chulalaksananukul, W., Cassava Pulp Enzymatic Hydrolysis Process as A Preliminary Step in 
Bio-alcohols Production from Waste Starchy Resources, J. Clean. Prod., 39, pp. 273-279, 2013.

[16] Yamaji, K., Matsumura, Y., Ishitani, H., Yamada, K., Wyman, C.E. \& Tolan, J.S., Production of Low-Cost Bioethanol to be A Rival to Fossil Fuel, New Energy and Industrial Technology Development Organization (NEDO), www.nedo.go.jp/itd/teian/ann-mtg/fy18/project_grant/pdf/h/h-0 3y_e.pdf., 2006 (16 May 2008).

[17] Yamaji, K., Yamamoto, H. \& Nagatomi, Y., Evaluation of Ethanol Production from Cassava Pulp in Thailand with a Biomass Collection and Utilization Model, in Proceedings of COE Symposium on Advanced Electronics for Future Generations-Secure Life Electronics for Quality Life and Society, pp. 329-335, 2007.

[18] Kosugi, A., Kondo, A., Ueda, M., Murata, Y., Vaithanomsat, P., Thanapase, W., Arai, T. \& Mori, Y., Production of Ethanol from Cassava Pulp via Fermentation with A Surface Engineered Yeast Strain Displaying Glucoamylase, Renew. Energ., 34, pp. 1354-1358, 2009.

[19] Nair, M.P.D., Padmaja, G. \& Moorthy, S.N., Biodegradation of Cassava Starch Factory Residue Using a Combination of Cellulases, Xylanases and Hemicellulases, Biomass Bioenerg., 35, pp. 1211-1218, 2011.

[20] Weerachanchai, P., Leong, S.S.J., Chang, M.W., Ching, C.B. \& Lee, J.M., Improvement of Biomass Properties by Pretreatment with Ionic Liquids for Bioconversion Process, Bioresource Technol., 111, pp. 453459, 2012.

[21] Taherzadeh, M.J. \& Karimi, K., Acid-Based Hydrolysis Processes for Ethanol from Lignocellulosic Materials: A Review, BioResources, 2(3), pp. 472-499, 2007.

[22] Fontana, J.D., Mitchell, D.A., Molina, O.E., Gaitan, A., Bonfim, T.M.B., Adelmann, J., Grzybowski, A. \& Passos, M., Starch Depolymerization with Diluted Phosphoric Acid and Application of The Hydrolysate in Astaxanthin Fermentation, Food Technol. Biotech., 46(3), pp. 305-310, 2008.

[23] Matsumoto, A., Tsubaki, S., Sakamoto, M. \& Azuma, J., A Novel Saccharification Method of Starch Using Microwave Irradiation with Addition of Activated Carbon, Bioresource Technol., 102, pp. 39853988, 2011.

[24] Chum, H.L., Johnson, D.K., Black, S.K. \& Overend, R.P., PretreatmentCatalyst Effects and The Combined Severity Parameter, Appl. Biochem. Biotech., 24/25, pp. 1-14, 1990.

[25] Chum, H.L., Johnson, D.K. \& Black, S.K., Organosolv Pretreatment of Enzymatic Hydrolysis of Poplars. 2. Catalyst Effects and The Combined Severity Parameter, Ind. Eng. Chem. Res., 29(2), pp. 156-162, 1990. 
[26] Teramoto, Y., Lee, S.H. \& Endo, T., Pretreatment of Woody and Herbaceous Biomass for Enzymatic Saccharification Using Sulfuric AcidFree Ethanol Cooking, Bioresource Technol., 99, pp. 8856-8863, 2008.

[27] Hermiati, E., Mangunwidjaja, D., Sunarti, T.C., Suparno, O. \& Prasetya, B., Microwave-Assisted Acid Hydrolysis of Starch Polymer in Cassava Pulp in The Presence of Activated Carbon, Procedia Chem., 4, pp. 238244, 2012.

[28] Warrand, J. \& Janssen, H.G., Controlled Production of Oligosaccharides from Amylose by Acid-Hydrolysis under Microwave Treatment: Comparison with Conventional Heating, Carbohyd. Polym., 69, pp. 353362, 2007.

[29] Whistler, R.L. \& Daniel, J.R., Carbohydrates, Food Chemistry, Fennema, O.R., ed., New York, Marcel Dekker, pp. 69-137, 1985.

[30] Thongchul, N., Navankasattusas, S. \& Yang, S.T., Production of Lactic Acid and Ethanol by Rhizopus oryzae Integrated with Cassava Pulp Hydrolysis., Bioprocess Biosyst. Eng., 33, pp. 407-416, 2010.

[31] Khan, A.R., Johnson, J.A. \& Robinson, R.J., Degradation of Starch Polymers by Microwave Energy, Cereal Chem., 56(4), pp. 303-304, 1979.

[32] Matsumoto, A., Tsubaki, S., Sakamoto, M. \& Azuma, J., Oligosaccharides Adsorbed on Activated Charcoal Powder Escaped from Hydrolysis by Microwave Heating in Water, in Proceedings of Global Congress on Microwave Energy Applications, pp. 785-788, 2008. 